\title{
Targeting therapy to minimize antimicrobial use in preweaned calves: Effects on health, growth, and treatment costs
}

\author{
A. C. B. Berge, ${ }^{*}$ D. A. Moore,$\dagger^{1}$ T. E. Besser, $\dagger$ and W. M. Sischo $\dagger$ \\ ${ }^{*}$ Berge Veterinary Consulting, Helsingborg, Sweden \\ †College of Veterinary Medicine, Washington State University, Pullman 99164
}

\begin{abstract}
Prophylactic and therapeutic antimicrobial use in food animals is questioned because of the potential for development of resistant bacteria and future inability to use some antimicrobials for human or animal disease. The objectives of this study were to determine the effect of raising preweaned dairy calves without antimicrobials in the milk and minimizing therapeutic antimicrobial treatment on morbidity, mortality, weight gain, and treatment costs. Newborn calves (n $=358$ ) were allocated to 1 of 4 groups, housed outdoors in individual hutches, and monitored for $28 \mathrm{~d}$. Calves in the conventional therapy (CT) group were treated as per dairy protocol with sulfamethoxazole/ trimethoprim, spectinomycin, penicillin, and bismuthpectin for diarrhea. The targeted therapy (TT) group included bismuth-pectin for diarrhea and antimicrobial treatment only in cases of fever or depressed attitude. Within CT and TT groups, calves were equally assigned to receive neomycin and tetracycline in their milk for the first 2 wk of life (AB-milk) or no antimicrobials (NoAB-milk). Daily health evaluations included fecal consistency, respiratory disease, attitude, and hydration status as well as milk and grain consumption. A negative binomial model evaluated the total number of days with diarrhea days in each group. General linear models were used to assess average daily weight gain and grain consumption. Conventionally treated calves had $70 \%$ more days with diarrhea than TT calves, and AB-milk calves had $31 \%$ more days with diarrhea compared with NoAB-milk calves. The TT calves tended to have a higher average daily gain by $28 \mathrm{~d}$ and consumed more grain compared with CT calves. If antimicrobials were used only for diarrhea cases with fever, inappetence, or depression and no in-milk antimicrobials were used, a $\$ 10$ per calf savings could be realized. Targeting antimicrobial therapy of calf diarrhea cases is prudent not only to save the drugs for future use but also to
\end{abstract}

Received March 10, 2009

Accepted May 20, 2009.

${ }^{1}$ Corresponding author: damoore@vetmed.wsu.edu prevent the potential for antibiotic-associated diarrhea and reduce calf-rearing costs.

Key words: dairy calf, diarrhea, antimicrobial agent, herd health

\section{INTRODUCTION}

Because of concerns that antimicrobial use in food animal production has the potential to increase antimicrobial resistance in human pathogens, alternative strategies to widespread antimicrobial use are needed (FAO/WHO/OIE, 2007; Silbergeld et al., 2008). In the United States, prophylactic antimicrobials are often added to milk or milk replacers for calves and several antimicrobials are used to treat preweaning diarrheal disease (Braidwood and Henry, 1990; Constable, 2003; Quigley et al., 1997; Silbergeld et al., 2008). Increasing pressure from the medical community and consumers to curtail antimicrobial use in animal agriculture has encouraged the development of management systems that minimize antimicrobial use (Torrence, 2001). Prudent drug use guidelines developed by the American Veterinary Medical Association state that "Prophylactic or metaphylactic use of antimicrobials should be based on a group, source, or production unit evaluation rather than being utilized as standard practice...." (DHHS:FDA:CVM, 2000). However, in a recent survey of 113 dairy farms in Pennsylvania, calves on $70 \%$ of the dairies were fed medicated milk replacers containing oxytetracycline and neomycin (Sawant et al., 2005). In a national study representing about $80 \%$ of US dairy operations, $57.5 \%$ of dairy producers fed medicated milk replacers to preweaned heifers in 2007 (USDA-APHIS, 2008). A tetracycline/neomycin combination was most commonly used (49.5\% of operations). In the same study, almost $18 \%$ of preweaned heifers were treated with antimicrobials for diarrhea and about $11 \%$ were treated with antimicrobials for respiratory disease.

Subtherapeutic levels of antimicrobials, such as tetracycline and neomycin added to milk or milk replacers, are used by producers for disease prophylaxis, feed efficiency, and growth promotion (McEwen and FedorkaCray, 2002). They are fed for specific, critical periods 
during a calf's life and then discontinued. Although enteric flora resistance, at least to penicillin, appears to depend on the dose of antimicrobials fed (Langford et al., 2003), persistence of resistance beyond the time of feeding is unknown. One study indicated that discontinuing the practice of feeding medicated milk replacers to calves decreased tetracycline resistance in Escherichia coli and Salmonella on dairy farms without increasing morbidity (Kaneene et al., 2008).

Therapeutic antimicrobials are needed to treat infectious causes of disease. Because calf diarrhea is the leading cause of mortality in preweaned calves, veterinarians and producers have relied on over-the-counter and prescription uses of antimicrobials as part of treatment protocols for cases of calf diarrhea (USDAAPHIS, 2008). Although many causes of diarrhea are not bacterial, Constable (2004) noted that the use of antimicrobials may be justified in these cases because of the evidence for $E$. coli overgrowth in the small intestine that may persist after the inciting pathogen is gone. Colonization of the small intestine by coliforms is associated with intestinal dysfunction and bacteremia, both clinical implications for antimicrobial use.

Antimicrobials are likely used because of the fear of mortality caused by bacteremia but the usage appears more common than actually warranted, resulting in concerns for the continued effectiveness of these drugs for animals and people. Strategies to reduce antimicrobial use but maintain calf health and welfare are needed. The objectives of this clinical trial were to determine the effect of raising preweaned dairy calves without antimicrobials in the milk and using less antimicrobials for treatment of diarrhea on the outcomes of morbidity, mortality, weight gain, and treatment.

\section{MATERIALS AND METHODS}

\section{Study Farm}

A large dairy farm that raised its own heifer and bull calves participated in the trial. From previous work with this farm, colostrum management was found to be good (few failures of passive transfer) and preweaning calf mortality was low $(<3 \%)$. Despite these findings, the farm reported a high treatment rate (about 90\%) of preweaned calves.

\section{Study Design and On-Farm Procedures}

For this clinical trial, we assumed a type I error $=$ 0.05 and a type II error $=0.10$. To detect a difference between a mean of 5 diarrhea days for conventionally treated calves compared with 4 diarrhea days for targeted therapy calves with a sample standard deviation of $3 \mathrm{~d}$, the estimated sample size (with a $15 \%$ loss to follow-up) was 70 calves per group.

Newborn dairy calves were randomly enrolled into 1 of 4 groups, allocated in birth-order sequence to wooden triplet hutches with heifers and bulls for breeding in one row and calves destined for beef in another row. Information on calving difficulties was obtained from dairy records. Dystocia was recorded as "no assistance," "assisted calving," and "difficult calving." Each triplet of hutches was separated by about $30 \mathrm{~cm}$ and placed on straw that was replaced twice weekly. A blood sample was drawn from each calf into an EDTA tube and a serum separator tube (both from Becton Dickinson, Franklin Lakes, NJ) on d 2. All calves were fed twice daily with approximately $2 \mathrm{~L}$ of pasteurized waste milk in buckets. Water was provided ad libitum between milk feedings, and grain intake was measured every third day. Calves were weighed on a scale with precision to the nearest $0.4 \mathrm{~kg}$ at the time of transfer into the hutches, at $28 \mathrm{~d}$ and at the time of weaning (about 60 d) to estimate average daily weight gain (ADG). The birth weights were classified as low $(\leq 35 \mathrm{~kg})$, medium $(35.5-44.5 \mathrm{~kg})$, and high $(\geq 45 \mathrm{~kg})$.

The triplet hutches were alternately assigned to have each of the 3 calves receive antimicrobials in the milk (AB-milk: $0.054 \mathrm{~g}$ of neomycin sulfate and $0.108 \mathrm{~g}$ of tetracycline $\mathrm{HCl}$ per day, as per farm practices) or not (NoAB-milk). The medicated supplement was added directly to the buckets at the time of feeding before adding milk and study personnel were blinded as to which calves received antimicrobials in the milk. Heifer and bull calves in one row of 200 hutches were assigned to the dairy's conventional treatment (CT) for diarrhea (1.5 million IU of penicillin G benzathine and penicillin $\mathrm{G}$ procaine subcutaneously twice a day for one day, trimethoprim-sulfa tablets $320 \mathrm{mg}$ per os twice a day, and spectinomycin sulfate $15 \mathrm{mg} / \mathrm{kg}$ subcutaneously once daily for $1 \mathrm{~d}$; approximate weight of calves at treatment $=44 \mathrm{~kg}$ ). Calves destined for beef were assigned to a separate row and received targeted treatment (TT) when needed. The dairy did not allow any changes to treatment protocols for heifers, but did allow for evaluation of TT in calves destined for beef (bull calves and freemartins). A set of 12 bulls destined for beef were also added to the CT group to account for possible differences that could be attributed to sex.

All calves were independently evaluated and scored daily by study personnel for mortality, morbidity, and milk intake as described previously (Table 1; Berge et al., 2005). Grain consumption was recorded in 3-d intervals for $28 \mathrm{~d}$. Calves refusing to drink more than half the milk fed were tube-fed and recorded as inappetent. Treatments were recorded on cards placed on the hutches. Dairy managers were instructed to not 
Table 1. Daily health evaluations, health scoring system, and targeted therapy protocols in a clinical trial evaluating a targeted therapy strategy to minimize antimicrobial prophylactic and therapeutic use in preweaned dairy calves ${ }^{1}$

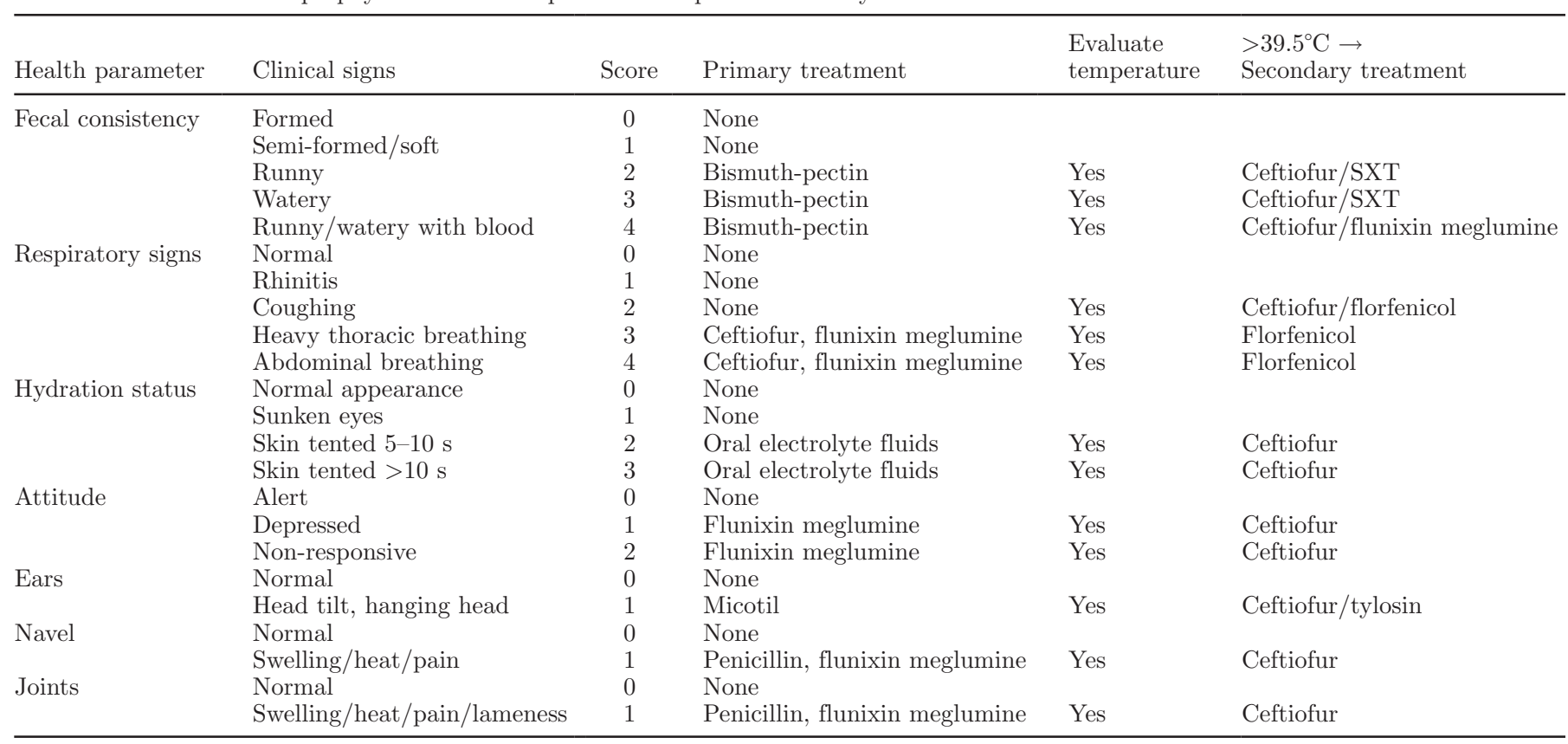

${ }^{1}$ Treatments: ceftiofur $=2 \mathrm{mg} / \mathrm{kg} ; \mathrm{SXT}=$ sulfa/trimethoprim tablets $160 \mathrm{mg}$ per $20 \mathrm{~kg}$ twice a day; flunixin meglumine $=2 \mathrm{mg} / \mathrm{kg}$ i.v.; florfeni$\mathrm{col}=20 \mathrm{mg} / \mathrm{kg} ;$ tilmicosin $=10 \mathrm{mg} / \mathrm{kg} ;$ tylosin $=18 \mathrm{mg} / \mathrm{kg}$.

modify the conventional treatment strategy during the study period. The treatments for the 2 TT groups were performed by study personnel (Table 1). Treatment for diarrheal disease included bismuth suspension (Bis-Co-sorb, Nich Marketers Inc., Columbus, OH) and electrolytes in water in cases of dehydration. Rectal temperatures of all TT calves with signs of disease or inappetence were taken with a digital thermometer. Calves with fever (temperature $\geq 39.5^{\circ} \mathrm{C}$ ), depressed attitude, or inappetence were treated with antimicrobials (Table 1).

\section{Laboratory Procedures}

From serum samples, total proteins (TP, g/dL) were determined using a refractometer and IgG concentration $(\mathrm{mg} / \mathrm{dL})$ using radial immunodiffusion (VMRD, Pullman, WA). Transfer of passive immunity was classified according to the IgG kit manufacturer's recommendations as failure of transfer of passive immunity (FTPI) for IgG $\leq 800 \mathrm{mg} / \mathrm{dL}$, partial failure of transfer of passive immunity (PFTPI) for IgG values 801 to $1,599 \mathrm{mg} / \mathrm{dL}$, and adequate transfer of passive immunity (ATPI) for IgG $\geq 1,600 \mathrm{mg} / \mathrm{dL}$. Packed cell volume percentage (PCV) was determined using microcapillary tubes and centrifugation.

\section{Data Analysis}

Health and treatment data were recorded in a spreadsheet program (Excel, Microsoft Corp., Redmond, WA) and analyzed using SAS version 9.2 (SAS Institute Inc., Cary, NC). Mortality in calves during the first $28 \mathrm{~d}$ was evaluated using Kaplan-Meier (KM) survival plots. Very low mortality rates in each of the groups precluded further statistical analysis. Differences in incidence of diarrheal disease, respiratory disease, attitude, hydration status, and appetite between treatment groups were tested with Mantel-Haenzel (MH) Chisquare statistics or Jonkheere Terpstra (JT) nonparametric statistic for trends (Holland and Wolfe, 1973). The number of days a calf experienced diarrhea during the study days at risk $(28 \mathrm{~d})$ was described using a multivariate negative binomial model (Allison, 1995). Antimicrobials in the milk and treatment strategy were the main effects included. Potential confounding variables tested for inclusion were birth weight, IgG, TP, PCV, calving assistance, and sex.

A GLM calculating least squares means was used to compare treatment differences in ADG by $28 \mathrm{~d}$ of age and by weaning $(60 \mathrm{~d})$ and average daily grain intake. Least squares mean estimates and 95\% confidence intervals were calculated for main effects and covariates remaining in the models. Economic comparisons of treatments in the 4 groups were based on costs for medication and labor for treatments. Costs included the retail value of prophylactic and therapeutic medications and personnel time to perform treatments. The time for treatment was estimated to the nearest minute, and the value of labor was set at $\$ 10 / \mathrm{h}$. 
Table 2. Descriptive statistics of calves enrolled in a clinical trial evaluating a targeted therapy strategy to minimize preweaning prophylactic and therapeutic antimicrobials $(\mathrm{AB})$

\begin{tabular}{|c|c|c|c|c|}
\hline Item & \multicolumn{2}{|c|}{ Conventional treatment } & \multicolumn{2}{|c|}{ Targeted therapy } \\
\hline Heifers (n) & 85 & 89 & 0 & 6 \\
\hline Bulls (n) & 10 & 8 & 82 & 78 \\
\hline Mean serum $\operatorname{IgG}(\mathrm{mg} / \mathrm{dL})$ & 1,552 & 1,376 & 1,511 & 1,492 \\
\hline Serum $\mathrm{IgG} \leq 800 \mathrm{mg} / \mathrm{dL}(\%)$ & 17 & 24 & 11 & 10 \\
\hline Serum total protein $(\mathrm{g} / \mathrm{dL})$ & 5.6 & 5.5 & 5.6 & 5.7 \\
\hline Packed cell volume $(\%)$ & 29.5 & 29.1 & 27.9 & 28.2 \\
\hline Birth weight $(\mathrm{kg})$ & 39.5 & 40.0 & 43.4 & 40.4 \\
\hline Average daily gain $28 \mathrm{~d}(\mathrm{~kg})$ & 0.27 & 0.26 & 0.29 & 0.28 \\
\hline Average daily gain $60 \mathrm{~d}(\mathrm{~kg})$ & 0.67 & 0.65 & 0.67 & 0.70 \\
\hline Average daily grain intake (kg) & 0.16 & 0.17 & 0.21 & 0.18 \\
\hline
\end{tabular}

\section{RESULTS}

Over a 2-wk period in October 2007, 358 calves were enrolled. The average serum concentration of IgG was $1,481 \mathrm{mg} / \mathrm{dL}(\mathrm{SD}=704 \mathrm{mg} / \mathrm{dL})$. Seventeen percent of calves had FTPI, $46 \%$ had PFTPI, and $37 \%$ had ATPI (Table 2). Serum TP concentrations were normally distributed with a mean of $5.6(\mathrm{SD}=0.6)$. The $\mathrm{PCV}$ values were normally distributed with a mean of $28.7 \%$ (SD $=5.5 \%$ ). There were no significant differences between the 4 treatment groups for average PCV, serum IgG, or TP. Birth weights were normally distributed with 16 , 62 , and $22 \%$ of the calves in the low, medium, and high birth-weight categories, respectively (Table 2). The TT group calves had higher average birth weight compared with CT group calves. Assisted calving was experienced by $11.5 \%$ of calves and $0.5 \%$ of calves had a difficult calving but there were no significant group differences.

Only 4 calves died during the study period, 3 in the CT group and 1 in the TT group. All calves that died had FTPI or PFTPI. Stratified analysis indicated numerical differences in morbidity due to treatment strategy group and antimicrobials in the milk (Table $3)$. Over the 28-d trial period, the proportion of days with diarrhea was $9.1 \%$ of the total calf-days at risk. The CT calves had significantly higher crude estimates compared with TT calves ( $\mathrm{MH} P$-value $<0.0001$ ). Calves receiving antimicrobials in the milk also had a higher percentage of diarrhea days compared with calves not fed antimicrobials $(\mathrm{MH} P$-value $=0.0002)$. Calves with respiratory disease scores 3 and 4 (Table 2) were observed in $0.16 \%$ of the total days at risk. Calves in the TT groups had more respiratory disease signs (JT $P$-value $<0.0001)$ compared with $\mathrm{CT}$ calves but there was no difference between AB-milk and NoAB- milk calves for respiratory score $(\mathrm{JT} P$-value $=0.31)$ and attitude score $(\mathrm{JT} P$-value $=0.16)$. There were no differences among the 4 groups for hydration score (JT $P$-value $=0.33)$. The CT calves had more days with depressed attitude compared with TT calves (JT P-value $<0.0001)$. More days with joint disease were seen in TT compared with $\mathrm{CT}$ calves $(\mathrm{MH} P$-value $=0.0001)$ and in AB-milk compared with NoAB-milk calves $(\mathrm{MH}$ $P$-value $=0.0001)$. Calves with FTPI and PFTPI had higher risk for diarrhea compared with calves with ATPI $($ JT $P$-value $=0.002)$. The same trend was seen for calves with lower TP. No crude significant effects on any measure of morbidity were found for sex, birth weight, calving assistance, or PCV. The estimated medication and treatment labor costs were $\$ 12.4$ for the $\mathrm{CT}$ calves with AB-milk, $\$ 11.7$ for CT calves with NoAB-milk, $\$ 4.5$ for TT calves with AB-milk, and $\$ 2.1$ for TT calves with NoAB-milk (Table 3).

From the multivariate negative binomial model (Table 4), CT calves had 90\% higher risk for diarrhea compared with TT calves, and AB-milk calves had $28 \%$ greater risk for diarrhea compared with NoAB-milk calves. Calves with FTPI and PFTPI had 22 and 18\% increased risk for more days with diarrhea compared with calves with ATPI.

Birth weight had a significant effect on ADG up to 28 d (Table 5). Lower birth weight calves $(\leq 35 \mathrm{~kg})$ gained $0.11 \mathrm{~kg}$ more per day compared with calves weighing $\geq 45 \mathrm{~kg}$ at birth $(P=0.01)$. The $\mathrm{CT}$ calves gained $0.04 \mathrm{~kg}$ less per day compared with TT calves by 28 d, controlling for birth weight (Table 5). There was no significant effect of antimicrobials in the milk on ADG. The GLM for ADG at weaning did not have significant predictive value and is not shown. The average daily grain intake was $55 \mathrm{~g}$ higher in TT calves compared 
Table 3. Number of daily observations, days with disease symptoms, number of treatments, and costs of medications for calves in a clinical trial evaluating a targeted therapy strategy to minimize preweaning prophylactic and therapeutic antimicrobial (AB) use in dairy calves

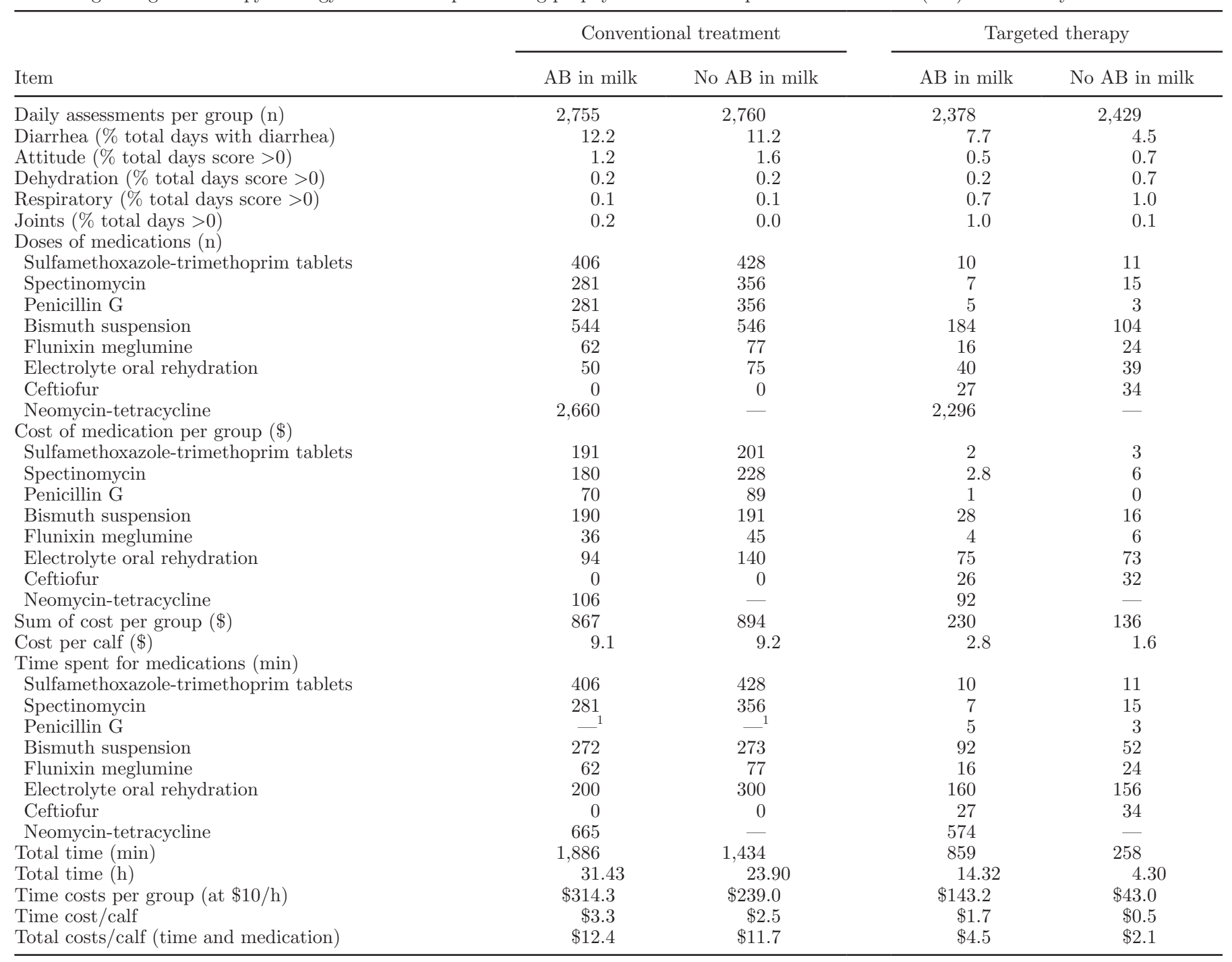

${ }^{1}$ Penicillin G was administered concurrently with spectinomycin, and time for this treatment is covered by time spent (min) for spectinomycin.

with CT calves, and calves in the higher birth weight category and female calves consumed more grain (Table $6)$.

\section{DISCUSSION}

This clinical trial demonstrates that, for this farm, with adequate transfer of passive immunity in calves, extensive use of antimicrobials for therapy and in the milk of preweaned calves may result in more diarrheal disease, lesser weight gain, and less grain consumption. The higher number of days with diarrhea in the CT group and in antimicrobial-fed calves may be caused by disturbance of the commensal enteric flora. In humans, studies have demonstrated changes to the ecology of the enteric microflora resulting in antibiotic-associated diarrhea (Sullivan et al., 2001; Young and Schmidt, 2004; Penders et al., 2006). Two possible mechanisms for antibiotic-associated diarrhea may be the antimicrobial effects on reducing the normal enteric flora's ability to resist colonization by pathogens or "overgrowth of indigenous, potentially pathogenic microorganisms" (Wagner et al., 2008).

Controlling for therapy group in the model, use of antimicrobials in the milk for these neonates resulted in $28 \%$ more days with diarrhea. Antimicrobials fed to neonatal calves increased the proportion of calves with diarrhea in 2 studies, one with neomycin only and one with neomycin and tetracycline (Shull and Frederick, 1978; Rollin et al., 1986). The farm dosages of in-milk 
Table 4. Results from a multivariate negative binomial model of the total number of days calves were observed with diarrhea during the first $28 \mathrm{~d}$ of life in a clinical trial evaluating a targeted therapy strategy to minimize preweaning prophylactic and therapeutic antimicrobial use in dairy calves

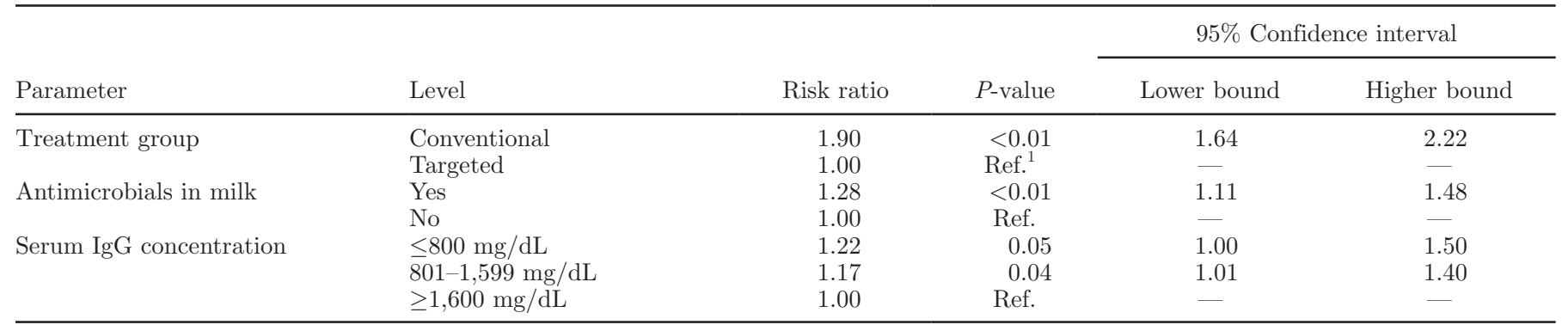

${ }^{1}$ Ref. $=$ referent category.

neomycin and tetracycline given to calves in this trial were much lower than these published studies (300 mg of neomycin in the published studies; $110 \mathrm{mg}$ of neomycin and $440 \mathrm{mg}$ of tetracycline hydrochloride estimated for a $44-\mathrm{kg}$ calf in the current study). The label dose for neomycin sulfate is $11 \mathrm{mg} / \mathrm{kg}$ (Constable, 2003).

In the TT group, each calf with diarrhea was evaluated for fever. Fever (rectal temperature $\geq 39.5^{\circ} \mathrm{C}$ ) was consistently associated with clinical signs of disease such as inappetence or depressed attitude. A system that notes and flags inappetence or other clinical signs of disease is likely the most practical way to target clinically sick animals that may require treatment in large calf-rearing operations. Assessing fever in animals with a depressed attitude or appetite is valuable to correctly diagnose likely infectious causes of disease and evaluate treatment response. Routine antimicrobial therapy of calves with diarrhea that are alert, have a good appetite, and are showing no other clinical signs does not appear to have value, and may even be detrimental for calf health.

The selection of antimicrobial for treatment should be based on the evidence. Constable notes that although several antimicrobials are labeled for enteric disease in calves, few have been the subject of clinical trials (Con- stable, 2004). Based on his review, only amoxicillin has been shown to be efficacious in the field, and treatment recommendations for neonatal calf diarrhea should focus on the use of broad-spectrum $\beta$-lactam drugs (e.g., amoxicillin, ampicillin, ceftiofur) and potentiated sulfonamides (e.g., trimethoprim/sulfadiazine). However, the use of oral or subcutaneous trimethoprim/sulfadiazine $(15 \mathrm{mg} / \mathrm{kg}$ of the drug combination $2.5 \mathrm{mg} / \mathrm{kg}$ trimethoprim and $12.5 \mathrm{mg} / \mathrm{kg}$ sulfadiazine) in different aged calves resulted in diminishing serum drug concentrations after just 1 wk of age (Guard et al., 1986). The trimethoprim portion in the serum of 1-wk-old calves was less than one-third the concentration compared with 1-d-old calves and was half the concentration in the synovial fluid. In ruminating calves (6 wk of age), there was little detectable trimethoprim in the serum or synovial fluid. However, it is likely that trimethoprim concentrations in the gastrointestinal tract may differ from these systemic values, and few data are available to assess the potential value of these orally administered drugs against enteric infections. Although many of the drugs used for neonatal calves are used extra-label, such treatment is warranted because treatment improves survivability (Berge et al., 2005). Bismuth-pectin was used as an "adsorbent." Although bismuth may have

Table 5. Results from a multivariate general linear model ${ }^{1}$ of $28-\mathrm{d}$ average daily gain $(\mathrm{kg})$ in a clinical trial evaluating a targeted therapy strategy to minimize preweaning prophylactic and therapeutic antimicrobial use in dairy calves

\begin{tabular}{|c|c|c|c|c|c|}
\hline \multirow[b]{2}{*}{ Parameter } & \multirow[b]{2}{*}{ Value } & \multirow[b]{2}{*}{ LSM estimate } & \multirow[b]{2}{*}{$P$-value } & \multicolumn{2}{|c|}{ 95\% Confidence interval } \\
\hline & & & & Lower bound & Higher bound \\
\hline \multirow[t]{2}{*}{ Treatment group } & Conventional & 0.26 & $<0.01$ & 0.24 & 0.28 \\
\hline & Targeted & 0.30 & Ref. $^{2}$ & 0.28 & 0.31 \\
\hline \multirow[t]{2}{*}{ Antimicrobials in milk } & Yes & 0.29 & 0.16 & 0.27 & 0.31 \\
\hline & No & 0.27 & Ref. & 0.26 & 0.29 \\
\hline \multirow[t]{3}{*}{ Birth weight category } & $\leq 35 \mathrm{~kg}$ & 0.34 & $<0.01$ & 0.32 & 0.37 \\
\hline & $\overline{35}-45 \mathrm{~kg}$ & 0.27 & $<0.01$ & 0.26 & 0.29 \\
\hline & $\geq 45 \mathrm{~kg}$ & 0.23 & Ref. & 0.20 & 0.25 \\
\hline
\end{tabular}

${ }^{1} F$-value $=5.93, \mathrm{df}=4, P$-value $<0.0001$, and $\mathrm{R}^{2}=0.10$.

${ }^{2}$ Ref. $=$ referent category. 
Table 6. Results from a multivariate general linear model ${ }^{1}$ of $28-\mathrm{d}$ average daily grain intake $(\mathrm{g})$ in a clinical trial evaluating a targeted therapy strategy to minimize prophylactic and therapeutic antimicrobial use in dairy calves

\begin{tabular}{|c|c|c|c|c|c|}
\hline \multirow[b]{2}{*}{ Parameter } & \multirow[b]{2}{*}{ Value } & \multirow[b]{2}{*}{ LSM estimate } & \multirow[b]{2}{*}{$P$-value } & \multicolumn{2}{|c|}{$95 \%$ Confidence interval } \\
\hline & & & & Lower bound & Higher bound \\
\hline Treatment group & Targeted & 208 & $\operatorname{Ref}^{2}$ & 189 & 227 \\
\hline \multirow[t]{2}{*}{ Antimicrobials in milk } & Yes & 182 & 0.79 & 169 & 194 \\
\hline & No & 179 & Ref. & 167 & 191 \\
\hline Birth weight category & $\leq 35 \mathrm{~kg}$ & 138 & $<0.01$ & 119 & 158 \\
\hline \multirow[t]{2}{*}{ Sex } & $\bar{F}$ emale & 200 & 0.02 & 180 & 220 \\
\hline & Male & 161 & Ref. & 143 & 178 \\
\hline
\end{tabular}

${ }^{1} F$-value $=12.24, \mathrm{df}=5, P$-value $<0.0001$, and $\mathrm{R}^{2}=0.15$.

${ }^{2}$ Ref. $=$ referent category.

some efficacy in binding endotoxin and as an antisecretory agent (Roussel and Brumbaugh, 1991), there is no evidence for the use of pectin (Merck, 2005).

In a previous study, calves with FTPI benefitted by being fed antimicrobials for the first week of life (Berge et al., 2005). However, evidence from this and numerous studies reaffirms the belief that calves with adequate transfer of passive immunity have significantly less mortality and morbidity and consequently will receive fewer antimicrobial treatments (Berge et al., 2005). In addition to transfer of passive immunity, other factors are associated with mortality and morbidity in neonatal calves. Calves with high or low birth weight, or packed cell volume and serum total proteins deviating from normal may influence the age of onset and duration of diarrhea (Pare et al., 1993). Dystocia (often associated with high birth weights) may influence the health and survival of calves (Lombard et al., 2007). In our study, low birth weight was associated with higher ADG but less grain consumption. The smaller neonates were likely more able to meet their growth needs through milk consumption. Birth weight was not associated with the number of days that calves had diarrhea.

Signs of respiratory disease were significantly more prevalent in the TT groups compared with the CT groups. Calves in the TT groups were given ceftiofur or florfenicol for treatment, whereas most of the calves in the CT groups received trimethoprim/sulfa tablets, spectinomycin, and penicillin G. Treatment with antibiotics for prevention or metaphylaxis may decrease the incidence of bovine respiratory disease complex (Duff and Galyean, 2007). Thus, if most of the calves were treated, it might mimic mass therapy as is used for metaphylaxis and result in prevention of respiratory signs in these groups.

Treatment costs were significantly higher in CT calves compared with TT calves. In calves with ATPI, liberal use of antimicrobials is not warranted, may be detrimental to calf health, and adds to rearing costs. On this farm, changing to the TT protocol and eliminating antimicrobials in the milk could have saved about $\$ 10$ per calf. After the trial, the producer removed the in-feed antimicrobials and eliminated the trimethop$\mathrm{rim} / \mathrm{sulfa}$ tablets. Raising these economic issues with producers may be motivation enough to reduce antimicrobial use.

\section{CONCLUSIONS}

This study provides important information to dairy producers and their advisors with reasons to reduce antimicrobial use in preweaned calves. Use of antimicrobials without clinical signs for their indication can potentially lead to antibiotic-associated diarrhea, which could affect weight gains and increase costs of rearing calves.

\section{ACKNOWLEDGMENTS}

This study was conducted with Washington State University IACUC approval. The authors thank the herd managers and veterinarian for their assistance. This project was funded by a grant from USDA:CSREES.

\section{REFERENCES}

Allison, P. D. 1995. Estimating Cox regression models with PROC PHREG. Pages 111-183 in Survival Analysis Using SAS, A Practical Guide. SAS Institute Inc., Cary, NC.

Berge, A. C., P. Lindeque, D. A. Moore, and W. M. Sischo. 2005. A clinical trial evaluating prophylactic and therapeutic antibiotic use on health and performance of preweaned calves. J. Dairy Sci. $88: 2166-2177$.

Braidwood, J. C., and N. W. Henry. 1990. Clinical efficacy of chlortetracycline hydrochloride administered in milk replacer to calves. Vet. Rec. 127:297-301.

Constable, P. D. 2003. Use of antibiotics to prevent calf diarrhea and septicemia. Bovine Pract. 37:137-142. 
Constable, P. D. 2004. Antimicrobial use in the treatment of calf diarrhea. J. Vet. Intern. Med. 18:8-17.

DHHS:FDA:CVM (Department of Health and Human Services Food and Drug Administration Center for Veterinary Medicine). 2000. Judicious use of antimicrobials for dairy cattle veterinarians. http://www.fda.gov/cvm/Documents/JUDAIRY.pdf Accessed Jun. 1, 2008.

Duff, G. C., and M. L. Galyean. 2007. Recent advances in management of highly stressed, newly received feedlot cattle. J. Anim. Sci. $85: 823-840$.

FAO/WHO/OIE. 2007. Report of the Joint FAO/WHO/OIE expert meeting on critically important antimicrobials. Rome, Italy November 26-30, 2007. http://www.who.int/foodborne_disease/ resources/Report\%20joint\%20CIA\%20Meeting.pdfAccessed June $1,2008$.

Guard, C. L., W. S. Schwark, D. S. Friedman, P. Blackshear, and M. Haluska. 1986. Age-related alterations in trimethoprim-sulfadiazine disposition following oral or parenteral administration in calves. Can. J. Vet. Res. 50:342-346.

Holland, M., and D. A. Wolfe. 1973. Nonparametrical Statistical Methods. John Wiley and Sons, New York, NY.

Kaneene, J. B., L. D. Warnick, C. A. Bolin, R. J. Erskine, K. May, and R. A. Miller. 2008. Changes in tetracycline susceptibility of enteric bacteria following switching to nonmedicated milk replacer for dairy calves. J. Clin. Microbiol. 46:1968-1977.

Langford, F. M., D. M. Weary, and L. Fisher. 2003. Antibiotic resistance in gut bacteria from dairy calves: A dose response to the level of antibiotics fed in milk. J. Dairy Sci. 86:3963-3966.

Lombard, J. E., F. B. Garry, S. M. Tomlinson, and L. P. Garber. 2007. Impacts of dystocia on health and survival of dairy calves. J. Dairy Sci. 90:1751-1760.

McEwen, S. A., and P. J. Fedorka-Cray. 2002. Antimicrobial use and resistance in animals. Clin. Infect. Dis. 34(Suppl. 3):S93-S106.

Merck. 2005. Pharmacology. Pages 1940-2184 in The Merck Veterinary Manual. C. M. Kahn and S. Line, ed. Merck \& Co., Inc., Whitehouse Station, NJ.

Pare, J., M. C. Thurmond, I. A. Gardner, and J. P. Picanso. 1993. Effect of birthweight, total protein, serum IgG and packed cell volume on risk of neonatal diarrhea in calves on two California dairies. Can. J. Vet. Res. 57:241-246.

Penders, J., C. Thijs, C. Vink, F. F. Stelma, B. Snijders, I. Kummeling, P. A. Brandt, and E. E. Stobberingh. 2006. Factors influencing the composition of the intestinal microbiota in early infancy. Pediatrics 118:511-521.

Quigley, J. D., J. J. Drewry, L. M. Murray, and S. J. Ivey. 1997. Body weight gain, feed efficiency, and fecal scores of dairy calves in response to galactosyl-lactose or antibiotics in milk replacers. J. Dairy Sci. 80:1751-1754.

Rollin, R. E., K. N. Mero, P. B. Koziek, and R. W. Phillips. 1986 Diarrhea and malabsorption in calves associated with therapeutic doses of antibiotics: Absorptive and clinical changes. Am. J. Vet. Res. 47:987-991.

Roussel, A. J., and G. W. Brumbaugh. 1991. Treatment of diarrhea of neonatal calves. Pages 713-728 in Applied Pharmacology and Therapeutics I. Vet. Clin. North Am Food Anim. Pract. K. W. Hinchcliff and A. D. Jernigan, ed. WB Saunders, Philadelphia, PA.

Sawant, A. A., L. M. Sordillo, and B. M. Jayarao. 2005. A survey on antibiotic usage in dairy herds in Pennsylvania. J. Dairy Sci 88:2991-2999.

Shull, J. J., and H. M. Frederick. 1978. Adverse effect of oral antibacterial prophylaxis and therapy on incidence of neonatal calf diarrhea. Vet. Med. Small Anim. Clin. 73:924-930.

Silbergeld, E. K., J. Graham, and L. B. Price. 2008. Industrial food animal production, antimicrobial resistance, and human health. Annu. Rev. Public Health 29:151-169.

Sullivan, A., C. Edlund, and C. E. Nord. 2001. Effect of antimicrobia agents on the ecological balance of human microflora. Lancet Inf Dis. 1:101-114.

Torrence, M. E. 2001. Activities to address antimicrobial resistance in the United States. Prev. Vet. Med. 51:37-49.

USDA-APHIS (Animal Plant Health Inspection Service). 2008. Antimicrobial use on US dairy operations, 2002 and 2007. N534.1008. USDA, Fort Collins, CO.

Wagner, R. D., S. J. Johnson, and C. E. Cerniglia. 2008. In vitro model of colonization resistance by the enteric microbiota: effects of antimicrobial agents used in food-producing animals. Antimicrob. Agents Chemother. 52:1230-1237.

Young, V. B., and T. M. Schmidt. 2004. Antibiotic-associated diarrhea accompanied by large-scale alterations in the composition of the fecal microbiota. J. Clin. Microbiol. 42:1203-1206. 